\title{
Recent patent applications in fluorescent imaging
}

\begin{abstract}
Patent number Description
DE 102008049878, A sample high-resolution imaging method for laser WO 2010037487 scanning microscopes involving recording fluorescent light and obtaining an optimal adjustment for a parameter of illumination and/or parameter of recording, e.g., wavelength of illumination, pulse sequence of illumination, wavelength range of recording, exposure time of recording and amplification of recording.

JP 2010071662 A spectral image processing method involving calculating the contribution of fluorescent materials with respect to the position of the material to be observed based on intrinsic emission spectrum and measurement spectral image.

WO 2010032306 A fluorescence image detecting apparatus for imaging cells, e.g., cancer cells, with a fluorescence side filter comprising interference and absorption filters arranged in a series along the fluorescence light-advancing direction.

US 20100068752 New substituted quinolinium compounds useful for labeling, detecting or quantifying target molecules, e.g., proteins and nucleic acids, identifying specific organelles or regions in cells of interest and multi-color imaging.
\end{abstract}

WO 2010030119, Fluorescent silica nanoparticles useful for the KR 2010030194 detection of lymph nodes, preferably sentinel nodes, for in vivo imaging of lymph nodes, monitoring cell lines, etc.

WO 2010030120, Fluorescent silica nanoparticles useful for detecting KR 2010030195 positron emission tomography and fluorescence dual imaging, comprising radioisotope labeling.

US 20100062429, A new fluorescent compound, 1,4-bis(2-

WO 2010028349 (dimethylamino) ethylamino)-2,3-difluoro-5,8dihydroxyanthracene-9,10-dione, for identifying the location or position of nuclei of cells.

US 20100055701, A new imaging agent comprising a fusion protein havCN 101659705 ing DNA binding domains and fluorescent domains; useful for imaging a cell and in screening assays for testing the activity of biological effector molecules.

FR 2934954, WO 2010018216

An indocyanine green formulation in nanoemulsion form used as a diagnostic agent for imaging fluorescence, comprising a continuous aqueous phase and dispersed oily phase comprising the indocyanine green, amphiphilic lipid and lipid solubilizer.

JP 2010014469 A method of manufacturing a radiological image conversion panel, e.g., imaging plate and scintillator panel, involving forming a fluorescent substance layer on a substrate and maintaining the initial temperature and final temperature of the substrate.
Nikon (Tokyo)

Mimura M

$9 / 16 / 2008$

$4 / 2 / 2010$

Shimadzu

Hizume K, Oda I,

9/18/2008 3/25/2010

(Kyoto, Japan)

Cox HJ, Pande P,

Patton WF, Xiang $Y$

Cox $\mathrm{HJ}$, Pande $\mathrm{P}$

$5 / 24 / 2005$

$3 / 18 / 201$

Tsunazawa Y, Yajima A

Patton WF, Xiang $Y$
Priority

application Publication

date date

empe M, Kleppe I,

Krampert G,

Wolleschensky $\mathrm{R}$

$4 / 8 / 2010$

SNU R\&DB Foundation

(Seoul), Seoul Nationa

University Foundation

(Seoul), Intellectual

Property \& Technology

Licensing Program

(Riyadh, Saudi Arabia)

SNU R\&DB Foundation

(Seoul), Seoul Nationa

University Foundation

(Seoul), Intellectual

Property \& Technology

Licensing Program

(Riyadh, Saudi Arabia)

Donegan JJ, Endo Life

Sciences (New York)

Li Z, Pande P,

Patton WF, Rabbani E,

Xiang $Y$

An $X$, Tong $Y$, Zhang

$X$, Beijing Institute

of Microbiology \&

Epidemiology (Beijing)

Atomic Energy and

Aiarfaj NA, Airessayes SI,

9/9/2008 3/18/2010, Aitamimi SA, Alothman ZA

$3 / 10 / 2010$

Choi G, Choi K, Chung D,

Gang $G$, Jeon $Y$, Jeong D,

Kang K, Kim Y, Kwon P,

Park J, Piao J, Quan B

Ahmed AYH, Aimajid AM,

Alothman AA, Alothman ZA,

9/9/2008 3/18/2010,

Choi G, Choi K, Chung D,

$3 / 18 / 2010$

Gang $G$, Jeon $Y$, Jeong $D$,

Kang K, Kim Y, Kwon P,

Park J, Piao J, Quan B

Donegan JJ, Li Z, Pande P, 9/8/2008 3/11/2010 Patton WF, Rabbani E,

Xiang $Y$

An $\mathrm{X}$, Tong $\mathrm{Y}$, Zhang $\mathrm{X}$

8/27/2008 3/4/2010,
Alternative Energies

Commission

(Gif-sur-Yvette, France)

Fuji Film (Tokyo)

Isoda Y, Takasu A

$7 / 2 / 2008$

$1 / 21 / 2010$

Texier NI

$2 / 18 / 2009$

\footnotetext{
Source: Thomson Scientific Search Service. The status of each application is slightly different from country to country. For further details, contact Thomson Scientific, 1800

Diagonal Road, Suite 250, Alexandria, Virginia 22314, USA. Tel: 1 (800) 337-9368 (http://www.thomson.com/scientific).
} 